\title{
Anticoagulant Therapy in Sepsis. The Importance of Timing
}

\author{
Ecaterina Scarlatescu ${ }^{1}$, Dana Tomescu1,2* ${ }^{*}$, Sorin Stefan Arama² \\ ${ }^{1}$ Department of Anesthesiology and Intensive Care III, Fundeni Clinical Institute, Bucharest, Romania \\ 2 University of Medicine and Pharmacy "Carol Davila", Bucharest, Romania
}

\begin{abstract}
Sepsis associated coagulopathy is due to the inflammation-induced activation of coagulation pathways concomitant with dysfunction of anticoagulant and fibrinolytic systems, leading to different degrees of haemostasis dysregulation. This response is initially beneficial, contributing to antimicrobial defence, but when control is lost coagulation activation leads to widespread microvascular thrombosis and subsequent organ failure. Large clinical trials of sepsis-related anticoagulant therapies failed to show survival benefits, but posthoc analysis of databases and several smaller studies showed beneficial effects of anticoagulants in subgroups of patients with early sepsis-induced disseminated intravascular coagulation. A reasonable explanation could be the difference in timing of anticoagulant therapy and patient heterogeneity associated with large trials. Proper selection of patients and adequate timing are required for treatment to be successful. The time when coagulation activation changes from advantageous to detrimental represents the right moment for the administration of coagulation-targeted therapy. In this way, the defence function of the haemostatic system is preserved, and the harmful effects of overwhelming coagulation activation are avoided.
\end{abstract}

Keywords: sepsis, Disseminated Intravascular Coagulation (DIC), anticoagulants

Received: 18 January 2017 / Accepted: 24 March 2017

\section{INTRODUCTION}

According to recent publications, sepsis is defined as a "life-threatening organ dysfunction due to a dysregulated host response to infection" [1,2]. Haematological disturbances are commonly encountered in critical care patients [3]. In septic patients a spectrum of coagulation activation is often noted, ranging from mild abnormalities on standard laboratory tests to disseminated intravascular coagulation (DIC), leading to bleeding complications and organ dysfunction [4]. The pathophysiology of sepsis-associated DIC was extensively investigated in recent studies and is a topic of interest, especially in the light of targeted antithrombotic therapies.

This article outlines the pathophysiology of inflammation-induced coagulation activation and reviews the anticoagulant-targeted therapies used for modulation of sepsis-associated coagulopathy.

\section{- INFLAMMATION-INDUCED ACTIVATION OF COAGULATION}

Coagulation derangement during sepsis is mainly attributed to tissue factor-mediated thrombin generation, dysfunction of normal physiologic anticoagulant systems and fibrinolytic mechanisms. This results in an enhanced fibrin formation followed by impairment of fibrin removal [5].

Coagulation activation during infections is triggered by the release of pro-inflammatory cytokines leading to the expression of tissue factor (TF) by different cell types [6]. Generally, TF is expressed in the extravascular compartments on cells which come in contact with blood only after vascular injury. During inflammation, circulating cells, mostly monocytes, and endothelial cells express TF on the membrane surface $[6,7]$.

On contact with blood, TF forms a complex with FVIIa. This complex activates FX and FIX, eventually leading to a thrombin burst with fibrin formation on 
phospholipid surfaces [8]. During inflammatory states, $\mathrm{TF}$ is not only expressed on endothelial or immune cells, but also on microparticles. These are circulating cell fragments derived from activated or apoptotic cells [9]. Neutrophils or eosinophils cannot express TF but can acquire it from monocyte-derived micro particles [10]. In this way, microparticles play a significant role in haemostasis activation and intercellular communication.

Neutrophil cells are involved in the early immune response, being directed by cytokines to infected tissues where the pathogens are destroyed either by intracellular killing after phagocytosis or by the use of extracellular traps (NETs). NETs are made up of DNA with histones and antimicrobial proteins [11]. Substances with antibacterial proprieties are released into the circulation by NETs and efficiently kill pathogens by surrounding them in an extracellular matrix [11, 12]. NETs can activate both the extrinsic and intrinsic coagulation pathways, promote platelet activation and endothelial wall damage and provide a platform for platelet or red blood cell adhesion and fibrin deposition [12]. Local coagulation activation by NETs contributes to the compartmentalization of bacteria. Thus NETs have important functions in antimicrobial defence, but when their production is uncontrolled, thrombus formation, tissue and organ damage can ensue [11].

Under normal conditions, the pro-coagulant response is followed by activation of fibrinolysis and clot dissolution. In the early stages of sepsis, increased expression of tissue plasminogen activator followed by increased fibrinolysis is noted only for a limited time. Afterwards, a rapid inhibition of fibrinolysis usually occurs due to increased synthesis of plasminogen activator inhibitor (PAI 1) and thrombin-activated fibrinolysis inhibitor (TAFI) [13, 14]. Fibrinolysisrelated markers have been the subject of studies investigating their role as diagnostic, prognostic biomarkers in septic patients [15].

\section{DTERAPEUTIC IMPLICATIONS}

Organ dysfunction in sepsis can be regarded as the consequence of uncontrolled inflammatory and pro-coagulant response to infection [5]. Inhibiting coagulation activation could be a useful tool to improve the effects of sepsis. However, it seems that local thrombosis plays a significant physiological role in immune defence, a concept called immunothrombosis. A small amount of local clot formation leads to the physical entrapment of pathogens by fibrin, limiting their dissemination into the circulation or nearby tissues $[12,16]$.

It is important to determine the exact timing for the start of coagulation-targeting therapy as this treatment may lead to bleeding complications if the coagulation system is already depleted [17]. However, a study using Pseudomonas Aeruginosa induced lung injury in animals, demonstrated that early inhibition of fibrin formation was associated with poorer outcomes [18].

\section{Activated Protein C}

Protein C is cleaved to form Activated Protein C (APC) on the endothelial cell surface, a process involving endothelial protein $\mathrm{C}$ receptor (EPCR) and thrombomodulin. EPCR is important for binding Protein $\mathrm{C}$ to the endothelium and the thrombin-thrombomodulin complex is necessary for Protein C activation [19]. APC and the cofactor Protein S irreversibly inactivate coagulation factors Va and VIIIa, thus limiting thrombin generation $[12,19]$. APC has significant profibrinolytic actions as it can inhibit both PAI-1 and TAFI [9]. Until recently, the current thought was that the anti-inflammatory activity of APC is due to the anticoagulant effect of decreasing thrombin generation [19]. According to recent research, APC has important anti-inflammatory proprieties independent of its anticoagulant activity. APC has multiple cytoprotective effects mediated by EPCR and a protease-activated receptor PAR-1. APC down-regulates the production of pro-inflammatory cytokines, of TF expression on activated leukocytes, decreases neutrophil adherence to endothelium and endothelial, and contributes to the endothelium stabilisation $[9,19]$. APC has additional beneficial effects by degrading histones from NETs [19].

Protein C levels are reduced in severe inflammatory states due to decreased synthesis and ongoing degradation by neutrophil elastases $[5,12]$. Furthermore, a significant downregulation of TM and EPCR due to inflammatory cytokines decreases protein $\mathrm{C}$ activation. In sepsis, low levels of free protein $\mathrm{S}$ contribute to the malfunction of the protein $\mathrm{C}$ system, resulting in a disruption of the balance between pro- and anticoagulant factors and a potential pro-thrombotic state $[5,20]$. Recent studies revealed that severe protein $C$ deficiency is septic patients is linked to the severity of organ dysfunction $[20,21]$. Based on the significant role of Protein $\mathrm{C}$ deficiency in the pathophysiology of sepsis-associated coagulopathy and subsequent organ 
failure, it appears logical to prescribe activated protein $\mathrm{C}$ as a treatment for sepsis.

The landmark "Protein C Evaluation in Severe Sepsis" (PROWESS) study showed a significant reduction in mortality at 28 days associated with the use of recombinant human activated protein C (rhAPC) [22]. Based on this study, the use of rhAPC was approved for treatment of septic patients with APACHE II scores of at least 24 [12]. Considering the high mortality associated with sepsis, the question arose as to whether rhAPC treatment could be extended to less sick patients. The follow-up multicentre trial [23] failed to show a survival benefit in patients treated with rhAPC. It was concluded that this therapy should not be used in patients with sepsis and single-organ failure or an APACHE II score of less than 25. A subsequent study (PROWESS-SHOCK) included patients with septic shock and failed to confirm an improved outcome associated with the use of rhAPC [24]. Based on this result, the manufacturer withdrew rhAPC from the market [25]. A Cochrane review confirmed the lack of benefits regarding survival in patients with severe sepsis and septic shock treated with rhAPC [25].

The disappointment expressed by the withdrawal of rhAPC based on the results of a single clinical trial, prompted the continued investigation of the benefits of this drug [5]. After analysing a large number of patients from the Surviving Sepsis Campaign's Database, Casserly et al. (2012) reported a reduction in in-hospital mortality rate associated with the use of rhAPC in septic patients with multiorgan failure [26]. A subgroup analysis of septic patients with overt DIC, defined according to a slightly modified ISTH criteria, revealed a greater relative risk reduction in mortality in rhAPCtreated patients compared to non-treated patients [27]. Small studies confirm the benefits of using plasma based APC which is still used in Japan [28, 29].

In conclusion, the failure of rhAPC trials may be related to treating septic patients without DIC. However, the uncertainty of when therapy should be initiated and the underestimation of bleeding risks remains controversial [9].

\section{Antithrombin}

Antithrombin (AT), a protease synthesised by the liver, is a natural inhibitor of thrombin as well as factors VIIa, IXa, Xa, XIa, XIIa [9, 12]. Without heparin, AT action is slow, the presence of heparin results in at least a 1000 fold increase in AT activity [5, 9]. Endogenous glycosaminoglycans on vessel walls promote AT-mediated inhibition of coagulation enzymes similar to heparin [5]. Independent of its anticoagulant function, AT possesses anti-inflammatory properties, increasing the production of prostacyclin from endothelial cells and decreasing the adhesion of leukocytes to endothelial cells by binding to receptors on neutrophils, monocytes and lymphocytes [30,31]. AT protects endothelial cells by binding and stabilising glycosaminoglycans that coat vascular endothelium, thus leading to decreased capillary permeability and leukocyte adhesion [32]. In severe inflammatory states, levels of circulating AT are usually low due to decreased AT synthesis, degradation by elastase from activated neutrophils and consumption by the formation of the thrombin-antithrombin complexes as a consequence of increased thrombin generation [5]. AT function is also reduced in inflammation due to the downregulation of glycosaminoglycans on the endothelial surface in response to proinflammatory cytokines [5,9]. The plasmatic level of AT was shown to be associated with the severity of organ failure in severe inflammatory states [33].

AT supplementation was another anticoagulant therapy tested in septic patients. The results of the largest trial, (KyberSept Trial, 2001) were interpreted contrarily in different countries, leading to differences in AT treatment recommendations [9]. The KyberSept trial failed to reveal efficacy concerning survival associated with the use of high-dose AT in severe sepsis patients but showed a trend towards a reduction in mortality at 28 and 90 days in the subgroup of patients without concomitant heparin therapy [34]. The concomitant use of heparin leads to decreased AT binding to glycosaminoglycans on cells membranes, reduces its anti-inflammatory action and endothelium-protective action [12]. A subsequent analysis, (Kienast et al. 2006) of a subgroup of patients with DIC and without heparin use, revealed decreased mortality at twenty-eight days [35] and corroborated the results from other trials and meta-analysis [36-39]. Monitoring AT levels offers guidance in the selection of patients and appropriate dosages [40].

However, a Cochrane review (Allingstrup, 2016) found insufficient evidence to support the use of AT in critically ill patients [41]. Considering the contradictory results, it is not surprising that the recommendations for AT use, differ. AT is recommended for treatment of septic DIC in Japanese guidelines, but not in those in Europe or the UK [9]. In Japan, anticoagulant 
therapy is commonly used in sepsis-associated DIC treatment, aimed at achieving AT levels within the normal range, a concept called "target activity-directed AT supplementation" [42].

The Japanese guidelines for the management of sepsis recommend the use of the Japanese Association of Acute Medicine (JAAM) DIC diagnostic criteria and AT plasmatic levels for selecting patients and the timing of anticoagulant therapy in sepsis. This is based on the assumption that treatment is appropriate only if administered in the earliest stage of DIC in patients with AT levels less than $70 \%[42,43]$.

\section{Thrombomodulin}

Thrombomodulin (TM), a thrombin receptor on the endothelial cell surfaces, has a major role in decreasing thrombin generation by causing protein $\mathrm{C}$ activation. TM has both APC-dependent and independent antiinflammatory effects, as well as an anticoagulant effect $[42,44]$. TM binds several inflammatory effectors as high-mobility group protein B1, histones or LPS.[12]. As the expression of TM is downregulated in sepsis, the therapeutic value of supplemental TM (recombinant thrombomodulin- rhTM) administration has been tested in several trials.

A randomised multicentre, double-blind controlled trial revealed significantly better resolution of DIC associated with the use of rhTM compared to heparin, in patients with haematologic malignancy or sepsis [45]. In a retrospective subgroup analysis of patients with sepsis-induced DIC included in this study, and treated with rhTM compared to heparin, there was a tendency towards a reduction in mortality at 28 days [46]. A Phase 2b, international, multicentre, doubleblind, randomized, placebo-controlled, parallel group, screening trial [47] proved that rhTM treatment was associated with a decrease in coagulation activation in patients with sepsis and DIC, but although mortality was reduced in the treatment group, it did not reach the efficacy target set at the beginning of the study. rtTM treatment proved safe when used as an adjunct to heparin [47]. Subsequent analysis revealed a significant reduction in thrombin generation markers in patients treated with rhTM compared to the placebo group [48].

In patients with sepsis-induced DIC, rhTM treatment was associated with a higher DIC resolution rate and improved mortality at twenty-eight days without any increase in the risk of bleeding [49].

A recent meta-analysis of all RCTs and observational studies, on the use of rhTM in patients with severe sep- sis, confirmed the trend towards a reduction in mortality rates [50]. Considering those encouraging results and the fact that rhTM treatment is recommended in sepsis-induced DIC treatment only in Japan, the results of the ongoing Phase 3 trial (ClinicalTrials.gov Identifier NCT01598831) are eagerly awaited.

\section{TFPI}

TFPI inhibits both factor Xa directly and complex VIIa-TF in a factor Xa-dependent manner. Through the ability to reduce thrombin generation, TFPI also decreases the activation of protease-activated receptors (PAR) resulting in an overall anti-inflammatory effect [51]. Reduced TFPI activity was demonstrated in sepsis, using animal models, probably due to degradation by plasmin and proteases $[52,53]$.

A large-scale a randomised controlled trial [54] showed that rTFPI in severe sepsis patients was effective in reducing thrombin activation markers, but failed to demonstrate a decrease in mortality in patients with a high INR. Post-hoc analysis revealed a trend towards reduced mortality rates in patients treated without concomitant heparin therapy [54]. Another large trial of rTFPI treated patients with severe community-acquired pneumonia, also failed to show a survival benefit [55].

Recently, two isoforms of TFPI have been described in humans. TFPI $\alpha$ and TFPI $\beta$ are expressed in different cell types and elevated under different conditions [51]. TFPI $\alpha$ has a major role in limiting clot growth, while TFPI $\beta$ inhibits TF mediated inflammation and cellular migration $[9,51]$.

\section{Heparin}

Unfractionated heparin (UFH) acts by way of maximising the effect of antithrombin, decreases platelet aggregation and prevents platelet-histone interaction [12]. When used in the placebo arms of several trials, heparin therapy was associated with a non-statistically significant reduction in mortality [12, 22, 34, 56]. A larger reduction in mortality in the Low Molecular Weight Heparin (LMWH) group compared with the UFH group, was shown in patients treated with drotrecogin alpha and concomitant prophylactic heparin [57].

A prospective randomised, double-blind study failed to demonstrate a benefit in either 28-day mortality or organ dysfunction scores, in heparin-treated patients compared to a placebo [58]. A small prospective study found that low-dose heparin improved organ failure 
scores and decreased the number of days of mechanical ventilation and hospitalisation when administered in the early stage of DIC [59].

A meta-analysis of trials investigating the use of heparin in septic patients, concluded that heparin reduced 28 days mortality rates without an increase in the bleeding risk [60]. A more recent systematic review and meta-analysis stated that the overall impact of heparin use in septic patients remains uncertain and more research is needed $[61,62]$.

In sepsis, histones play a significant role in activating coagulation contributing to endothelial dysfunction, microvascular thrombosis and organ failure [11]. Both unfractionated heparin (UFH) and non-anticoagulant heparin, bind histones, prevent histone-platelet interactions, decrease NETs-driven thrombin generation and mortality in animal models $[9,28,63]$. The use of non-anticoagulant heparin was associated with nonsignificant prolongation of bleeding time compared to UFH together with a reduction in the bleeding risk [63].

\section{NET- targeted therapy}

NETs are beneficial in the early phases and detrimental in the later stages of severe systemic infections. Targeting NETs or histones may be effective in improving the outcome of septic patients when NETs become deleterious [11]. Anti- NETs therapy is achieved by targeting NET derived extracellular DNA using DNAse or by targeting histones using antihistone antibodies or unfractionated heparin $[11,63]$.

\section{CONCLUSIONS}

The overall failure of trials to prove a reduction in mortality in septic patients, may be readressed by studies which identify the precise moment when the pro-coagulant response changes from a beneficial to a detrimental process. The assessment of coagulation either by using a panel of standard coagulation tests or global haemostasis tests, is mandatory for identifying patients who will benefit from anticoagulant therapy. Hitting upon the right time allows the avoidance of unwanted effects of too early administration of anticoagulants, but also of the unbeneficial late treatment, in patients with already exhausted haemostasis.

Overall, anticoagulant-targeted therapy seems to be an appropriate therapy to combat the deleterious effects of sepsis-associated coagulopathy.

\section{口CONFLICT OF INTEREST}

None to declare.

\section{REFERENCES}

1. Singer M, Deutschman CS, Seymour CW, et al. The Third International Consensus Definitions for Sepsis and Septic Shock (Sepsis-3). JAMA. 2016;315:801-10. doi: 10.1001/ jama.2016.0287.

2. Copotoiu S-M, Copotoiu R. Much Ado About the New Definitions of Sepsis. J Crit Care Med. 2016;2:67-72. doi: 10.1515/jccm2016-0015.

3. Rawal G, Kumar R, Yadav S, Singh A. Anemia in Intensive Care: A review of Current Concepts. J Crit Care Med. 2016;2:109-114. doi: 10.1515/jccm-2016-0017.

4. Semeraro $N$, Ammollo CT, Semeraro $F$, Colucci $M$. Sepsis, thrombosis and organ dysfunction. Thromb Res. 2012;129:290-5. doi: 10.1016/j.thromres.2011.10.013.

5. Levi M. The coagulant response in sepsis and inflammation. Hamostaseologie. 2010;30:10-6.

6. Wiersinga WJ, Levi M, van der Poll T: Coagulation in Sepsis. In Abraham E, Singer $M$, editors: Mechanisms of Sepsis-Induced Organ Dysfunction and Recovery. Berlin, Heidelberg: Springer. 2007, pp. 273-85.

7. Levi M, Poll T. Coagulation in patients with severe sepsis. Semin Thromb Hemost. 2015;41:9-15. doi: 10.1055/s-0034-1398376.

8. Mackman N. The many faces of tissue factor. J Thromb Haemost. 2009;7 Suppl 1:136-9. doi: 10.1111/j.1538-7836.2009.03368.x.

9. Iba T, Nagaoka I, Boulat M. The anticoagulant therapy for sepsisassociated disseminated intravascular coagulation. Thromb Res. 2013;131:383-9. doi: 10.1016/j.thromres.2013.03.012.

10. Pawlinski R, Mackman N. Cellular sources of tissue factor in endotoxemia and sepsis. Thromb Res. 2010;125 Suppl 1:S70-3. doi: 10.1016/j.thromres.2010.01.042.

11. Camicia G, Pozner R, de Larranaga G. Neutrophil extracellular traps in sepsis. Shock. 2014;42:286-94. doi: 10.1097/ SHK.0000000000000221.

12. Allen KS, Sawheny E, Kinasewitz GT. Anticoagulant modulation of inflammation in severe sepsis. World J Crit Care Med. 2015;4:105-15. doi: 10.5492/wjccm.v4.i2.105.

13. Prakash S, Verghese $S$, Roxby D, et al. Changes in fibrinolysis and severity of organ failure in sepsis: a prospective observational study using point-of-care test--ROTEM. J Crit Care. 2015;30:26470. doi: 10.1016/j.jcrc.2014.10.014

14. Zeerleder S, Schroeder V, Hack CE, Kohler HP, Wuillemin WA. TAFI and PAI-1 levels in human sepsis. Thromb Res. 2006;118:205-12. doi: 10.1016/j.thromres.2005.06.007.

15. Georgescu A-M, Szederjesi J, Voidăzan S, et al. Soluble urokinase-type plasminogen activator receptor (suPAR) - a possible biomarker for bacteremia in sepsis. Romanian Review of Laboratory Medicine. 2015;23:59-73. doi: 10.1515/rrlm- 
2015-0002.

16. Fiusa MM, Carvalho-Filho MA, Annichino-Bizzacchi JM, De Paula EV. Causes and consequences of coagulation activation in sepsis: an evolutionary medicine perspective. BMC Med. 2015;13:105. doi: 10.1186/s12916-015-0327-2.

17. Toh $\mathrm{CH}$, Alhamdi $\mathrm{Y}$, Abrams ST. Current Pathological and Laboratory Considerations in the Diagnosis of Disseminated Intravascular Coagulation. Ann Lab Med. 2016;36:505-12. doi: 10.3343/alm.2016.36.6.505.

18. Robriquet L, Collet F, Tournoys A, et al. Intravenous administration of activated protein $\mathrm{C}$ in Pseudomonas-induced lung injury: impact on lung fluid balance and the inflammatory response. Respir Res. 2006;7:1-10. doi: 10.1186/1465-9921-741.

19. Mosnier LO, Zlokovic BV, Griffin JH. The cytoprotective protein C pathway. Blood. 2007;109:3161-72. doi: 10.1182/ blood-2006-09-003004.

20. Shaw AD, Vail GM, Haney DJ, Xie J, Williams MD. Severe protein $C$ deficiency is associated with organ dysfunction in patients with severe sepsis.J Crit Care. 2011;26:539-45. doi: 10.1016/j. jcrc.2011.05.006.

21. Brunkhorst F, Sakr Y, Hagel S, Reinhart K. Protein C concentrations correlate with organ dysfunction and predict outcome independent of the presence of sepsis. Anesthesiology. 2007;107:15-23. doi: 10.1097/01.anes.0000267531.39410.d3.

22. Bernard GR, Vincent JL, Laterre PF, et al. Efficacy and safety of recombinant human activated protein $\mathrm{C}$ for severe sepsis. N Engl J Med. 2001;344: 699-709. doi: 10.1056/ nejm200103083441001.

23. Abraham E, Laterre P-F, Garg R, et al. Drotrecogin Alfa (Activated) for Adults with Severe Sepsis and a Low Risk of Death. N Engl J Med. 2005;353:1332-41. doi: doi:10.1056/NEJMoa050935.

24. Ranieri VM, Thompson BT, Barie PS, et al. Drotrecogin alfa (activated) in adults with septic shock. N Engl J Med. 2012;366:2055-64. doi: 10.1056/NEJMoa1202290.

25. Marti-Carvajal AJ, Sola I, Gluud C, Lathyris D, Cardona AF. Human recombinant protein $C$ for severe sepsis and septic shock in adult and paediatric patients. Cochrane Database Syst Rev. 2012;12:Cd004388. doi: 10.1002/14651858.CD004388. pub6.

26. Casserly B, Gerlach H, Phillips GS, et al. Evaluating the use of recombinant human activated protein $C$ in adult severe sepsis: results of the Surviving Sepsis Campaign. Crit Care Med. 2012;40:1417-26. doi: 10.1097/CCM.0b013e31823e9f45.

27. Dhainaut JF, Yan SB, Joyce DE, et al. Treatment effects of drotrecogin alfa (activated) in patients with severe sepsis with or without overt disseminated intravascular coagulation. J Thromb Haemost. 2004;2:1924-33. doi: 10.1111/j.15387836.2004.00955.x.

28. Iba T, Gando S, Thachil J. Anticoagulant therapy for sepsisassociated disseminated intravascular coagulation: the view from Japan. J Thromb Haemost. 2014;12:1010-9. doi: 10.1111/ jth.12596.
29. Aoki N, Matsuda T, Saito H, et al. A Comparative Double-Blind Randomized Trial of Activated Protein C and Unfractionated Heparin in the Treatment of Disseminated Intravascular Coagulation. Int J Hematol. 2002;75:540-7.

30. Levi $M$, van der Poll T. The role of natural anticoagulants in the pathogenesis and management of systemic activation of coagulation and inflammation in critically ill patients. Semin Thromb Hemost. 2008;34:459-68. doi: 10.1055/s-00281092876.

31. Minnema MC, Chang AC, Jansen PM, et al. Recombinant human antithrombin III improves survival and attenuates inflammatory responses in baboons lethally challenged with Escherichia coli. Blood. 2000;95:1117-23.

32. Chappell D, Jacob M, Hofmann-Kiefer K, et al. Antithrombin reduces shedding of the endothelial glycocalyx following ischaemia/reperfusion. Cardiovasc Res. 2009;83:388-96. doi: 10.1093/cvr/cvp097.

33. Iba T, Gando S, Murata A, et al. Predicting the severity of systemic inflammatory response syndrome (SIRS)-associated coagulopathy with hemostatic molecular markers and vascular endothelial injury markers. J Trauma. 2007;63:1093-8. doi: 10.1097/01.ta.0000251420.41427.d3.

34. Warren BL, Eid A, Singer $P$, et al. Caring for the critically ill patient. High-dose antithrombin III in severe sepsis: a randomized controlled trial. JAMA. 2001;286:1869-78.

35. Kienast J, Juers M, Wiedermann CJ, et al. Treatment effects of high-dose antithrombin without concomitant heparin in patients with severe sepsis with or without disseminated intravascular coagulation. J Thromb Haemost. 2006;4:90-7. doi: 10.1111/j.1538-7836.2005.01697.x.

36. Wiedermann CJ, Kaneider NC. A systematic review of antithrombin concentrate use in patients with disseminated intravascular coagulation of severe sepsis. Blood Coagul Fibrinolysis. 2006;17:521-6. doi: 10.1097/01. mbc.0000245302.18010.40.

37. Iba T, Saitoh D, Wada H, Asakura H. Efficacy and bleeding risk of antithrombin supplementation in septic disseminated intravascular coagulation: a secondary survey. Crit Care. 2014;18:497. doi: 10.1186/s13054-014-0497-x.

38. Iba T, Gando S, Saitoh D, et al. Efficacy and Bleeding Risk of Antithrombin Supplementation in Patients With Septic Disseminated Intravascular Coagulation. Clin Appl Thromb Hemost. 2016. doi: 10.1177/1076029616648405. [Epub ahead of print]

39. Gando S, Saitoh D, Ishikura H, et al. A randomized, controlled, multicenter trial of the effects of antithrombin on disseminated intravascular coagulation in patients with sepsis. Crit Care. 2013;17:R297. doi: 10.1186/cc13163.

40. IbaT, Saitoh D, Gando S, Thachil J. The usefulness of antithrombin activity monitoring during antithrombin supplementation in patients with sepsis-associated disseminated intravascular coagulation. Thromb Res. 2015;135:897-901. doi: 10.1016/j. thromres.2015.03.007. 
Available online at: www.jccm.ro

41. Allingstrup M, Wetterslev J, Ravn FB, Moller AM, Afshari A. Antithrombin III for critically ill patients. Cochrane Database Syst Rev. 2016;2:Cd005370. doi: 10.1002/14651858.CD005370. pub3.

42. Iba T, Thachil J. Present and future of anticoagulant therapy using antithrombin and thrombomodulin for sepsis-associated disseminated intravascular coagulation: a perspective from Japan. Int J Hematol. 2016;103:253-61. doi: 10.1007/s12185015-1904-z.

43. Oda S, Aibiki M, Ikeda $T$, et al. The Japanese guidelines for the management of sepsis. J Intensive Care. 2014;2:55. doi: 10.1186/s40560-014-0055-2.

44. King EG, Bauza GJ, Mella JR, Remick DG. Pathophysiologic mechanisms in septic shock. Lab Invest. 2014;94:4-12. doi: 10.1038/labinvest.2013.110.

45. Saito H, Maruyama I, Shimazaki S, et al. Efficacy and safety of recombinant human soluble thrombomodulin (ART-123) in disseminated intravascular coagulation: results of a phase III, randomized, double-blind clinical trial. J Thromb Haemost. 2007;5:31-41. doi: 10.1111/j.1538-7836.2006.02267.x.

46. Aikawa N, Shimazaki S, Yamamoto $Y$, et al. Thrombomodulin alfa in the treatment of infectious patients complicated by disseminated intravascular coagulation: subanalysis from the phase 3 trial. Shock. 2011;35:349-54. doi: 10.1097/ SHK.0b013e318204c019.

47. Vincent JL, Ramesh MK, Ernest D, et al. A randomized, doubleblind, placebo-controlled, Phase $2 \mathrm{~b}$ study to evaluate the safety and efficacy of recombinant human soluble thrombomodulin, ART-123, in patients with sepsis and suspected disseminated intravascular coagulation. Crit Care Med. 2013;41:2069-79. doi: 10.1097/CCM.0b013e31828e9b03.

48. Hoppensteadt D, Tsuruta K, Cunanan J, et al. Thrombin generation mediators and markers in sepsis-associated coagulopathy and their modulation by recombinant thrombomodulin. Clin Appl Thromb Hemost. 2014;20:129-35. doi: 10.1177/1076029613492875.

49. Kato T, Sakai T, Kato M, et al. Recombinant human soluble thrombomodulin administration improves sepsis-induced disseminated intravascular coagulation and mortality: a retrospective cohort study. Thromb J. 2013;11:3. doi: 10.1186/1477-9560-11-3.

50. Yamakawa K, Aihara M, Ogura H, et al. Recombinant human soluble thrombomodulin in severe sepsis: a systematic review and meta-analysis. J Thromb Haemost. 2015;13:508-19. doi: 10.1111/jth.12841.

51. Maroney SA, Hansen KG, Mast AE. Cellular expression and biological activities of alternatively spliced forms of tissue factor pathway inhibitor. Curr Opin Hematol. 2013;20:403-9.
The Journal of Critical Care Medicine 2017;3(2) • 69

doi: 10.1097/MOH.0b013e3283634412.

52. Lupu C, Herlea O, Tang H, Lijnen RH, Lupu F. Plasmin-dependent proteolysis of tissue factor pathway inhibitor in a mouse model of endotoxemia. J Thromb Haemost. 2013;11:142-8. doi: 10.1111/jth.12044.

53. Tang H, Ivanciu L, Popescu N, et al. Sepsis-induced coagulation in the baboon lung is associated with decreased tissue factor pathway inhibitor. Am J Pathol.. 2007;171:1066-77. doi: 10.2353/ajpath.2007.070104.

54. Abraham E, Reinhart K, Opal S, et al. Efficacy and safety of tifacogin (recombinant tissue factor pathway inhibitor) in severe sepsis: a randomized controlled trial. JAMA. 2003;290:238-47. doi: 10.1001/jama.290.2.238.

55. Wunderink RG, Laterre PF, Francois B, et al. Recombinant tissue factor pathway inhibitor in severe community-acquired pneumonia: a randomized trial. Am J Respir Crit Care Med. 2011;183:1561-8. doi: 10.1164/rccm.201007-11670C.

56. Polderman KH, Girbes AR. Drug intervention trials in sepsis: divergent results. Lancet. 2004;363:1721-3. doi: 10.1016/ s0140-6736(04)16259-4.

57. Levi M, Levy M, Williams MD, et al. Prophylactic heparin in patients with severe sepsis treated with drotrecogin alfa (activated). Am J Respir Crit Care Med. 2007;176:483-90. doi: 10.1164/rccm.200612-18030C.

58. Jaimes F, De La Rosa G, Morales C, et al. Unfractioned heparin for treatment of sepsis: A randomized clinical trial (The HETRASE Study). Crit Care Med. 2009;37:1185-96. doi: 10.1097/CCM.0b013e31819c06bc.

59. Liu XL, Wang XZ, Liu XX, et al. Low-dose heparin as treatment for early disseminated intravascular coagulation during sepsis: A prospective clinical study. Exp Ther Med. 2014;7:604-8. doi: 10.3892/etm.2013.1466.

60. Wang C, Chi C, Guo L, et al. Heparin therapy reduces 28-day mortality in adult severe sepsis patients: a systematic review and meta-analysis. Critical care. 2014;18:563. doi: 10.1186/ s13054-014-0563-4.

61. Zarychanski R, Abou-Setta AM, Kanji S, et al. The efficacy and safety of heparin in patients with sepsis: a systematic review and metaanalysis. Crit Care Med. 2015;43:511-8. doi: 10.1097/ ccm.0000000000000763.

62. Houston BL, Dwivedi DJ, Grin P, et al. Biological Rational for the Use of Heparin in Septic Shock: Translational Data from the Halo Pilot RCT. Blood. 2015;126:2336.

63. Wildhagen KC, Garcia de Frutos P, Reutelingsperger CP, et al. Nonanticoagulant heparin prevents histone-mediated cytotoxicity in vitro and improves survival in sepsis. Blood. 2014;123:1098-101. doi: 10.1182/blood-2013-07-514984. 